https://doi.org/10.48009/2_iis_2009_614-622

\title{
APPROPRIATE PENALTIES FOR ACADEMIC DISHONESTY AS PERCEIVED BY STUDENTS IN AN INFORMATION SYSTEMS CLASS: AN ANALYSIS BY CLASS LEVEL
}

\author{
Melody W. Alexander, Ball State University, malexand@bsu.edu \\ Allen D. Truell, Ball State University, atruell@bsu.edu \\ Jensen J. Zhao, Ball State University, jzhao@bsu.edu
}

\begin{abstract}
This focus of this study was to identify appropriate penalties for situations involving academic dishonesty (cheating) as perceived by college student. A secondary purpose was to document any differences in perceptions based on class level. A total of 266 students in introductory information systems courses completed an 18-item instrument at the end of the college semester. Results of the study revealed that the penalties perceived as appropriate for cheating differ among freshman, sophomores, and upper classmen (juniors and seniors). Areas of further research are suggested.
\end{abstract}

Keywords: Academic Dishonesty, Cheating, Penalties, Ethics, Information Systems

\section{INTRODUCTION}

Academic dishonesty is a critical issue facing educators. Cheating in all levels of education has been described as widespread, increasing, and alarming [10, 11, 23]. The Josephson Institute's 2008 Report Card on the Ethics of American Youth found that 64 percent of high school students reported they had cheated on tests in 2008, which was an increase of 4 percent from 2006 [6]. Numerous researchers have explored the causes and perceptions of cheating, both from faculty and students viewpoints $[2,19,20$, 22]. Volpe, Davidson, and Bell [24] reported that in general, teachers are underestimating the amount of cheating that is actually occurring in their classrooms.

In a study of university students conducted by Kidwell, Wozniak, and Laurel [8] over seventy percent reported that they had cheated on multiple occasions. The survey asked students about the seriousness of various forms of cheating, and the majority of students reported getting questions from someone who had already taken a test to be trivial cheating, or not cheating at all. Carter and Punyanunt-Carter [5] found that students reported some methods of addressing cheating on tests more acceptable than others. The results from a study conducted by Burrus, McGoldrick, and Schuhmann [1] indicated that students are not even aware of what constitutes cheating until some type of definition is given. Of additional concern are the changing views of what is considered appropriate, as new technologies such as cell phones and their capabilities have increased methods for cheating $[3,10,12,15]$

Although researchers have documented that students self-report that they cheat less than their peers, believing and observing their peers cheating motivated them to cheat $[1,2,4,13,14,19]$. Davy, Kincaid, Smith, and Trawick [6] found that students, who were aware that their peers were cheating, significantly increased the probability that they also would cheat. Megehee and Spake [13] reported the possibility that they might be caught, was not a deterrent to prevent students from cheating on homework and tests.

As ethical issues in the workplace are so widely publicized and discussed, the rise of academic dishonesty in education is disheartening. Numerous researchers have characterized the attitudes and motivators of students who cheat $[6,16,17]$. A goal of educators is to ensure that as students progress through their college career, ethical behavior would be understood and incidences of cheating behavior would be lessened. However, as Rawwas, Swaidan, and Isakson [18] point out, academic dishonesty and incidents where students put their self-interest above ethics is rising.

\section{NEED FOR THE STUDY}

The increasing rate of academic dishonesty at all levels of education is disturbing, and numerous researchers have recommended further research is crucial. As reported by King, Guyette, and Piotrowski [9] who studied online cheating, further research in relation to class level is needed. Research on college students' perceptions of the penalties for cheating and any differences based on class standing, however, is limited. Therefore, this study investigated the perceptions of students in an information systems class of the appropriate penalties for academic 
dishonesty. Further investigation identified any differences in perceptions of the appropriate penalty based on class standing.

\section{PURPOSE}

The purpose of this study was to document college students' perceptions of the appropriate penalties for academic dishonesty in an introductory information systems course. A secondary purpose was to identify if any differences exist in college students perceptions of appropriate penalties in relation to class level. To address this purpose, answers to the following research questions were investigated:

1. What are college students' perceptions of the appropriate penalties for academic dishonesty in an introductory information systems course?

2. Are there statistically significant differences in student perceptions of the appropriate penalties for academic dishonesty based on class level?

\section{PROCEDURES}

The procedures used to conduct the study are outlined in the following section and include a description of the study participants, instrument, data collection, and data analysis.

\section{Participants}

The participants for this study consisted of students enrolled in seven sections of an introductory information systems course offered at a mid-sized, Midwestern university. As required by Institutional Review Board (IRB) protocol, only students who were willing volunteers participated in the study. A total of 266 students volunteered to participate.

\section{Instrument}

As no instrument was found that directly addressed the study objectives, an 18-item survey instrument was developed by the researchers. The survey instrument was based on a review of literature, classroom experience, and discussions with students. The survey instrument included three sections: computer assignments, online testing, and personal integrity/responsibility. Each section contained six situations of academic dishonesty. Participants reported their perceptions of the appropriate penalty for each situation using a five-point Likert type scale. Scoring options were: a) no penalty, b) a grade of " 0 ," c) a grade of " 0 " and a required course on cheating/ethics, d) administratively withdrawn from the course with a failing grade, and e) withdrawn from the university. The academic dishonesty penalties were derived from the researchers' university's Faculty and Professional Personnel Handbook.

Instrument Validation. The survey instrument was reviewed for validity by a 10-member panel of experts. The panel of experts included information systems faculty, information systems researchers, and university computing services administrators. The panel's evaluation indicated that the survey met the researchers' stated objectives.

Instrument Clarification. Clarity of the instrument's directions and individual questions was pilot tested with a volunteer group of 31 students from an advanced information systems course. Since no difficulties were reported by the pilot group, no changes in wording or length were made to the survey.

\section{Data Collection}

During the last week of the fall semester, students enrolled in seven sections of an introductory information systems course were asked to complete an online survey regarding their perceptions of the appropriate penalties for academic dishonesty. A total of 226 students volunteered to participate in the study. Students were informed during survey administration that participation in this study was voluntary, anonymous, and would not have an impact on their final course grade, as required by the university IRB.

\section{Data Analysis}

In accordance with the university's IRB guidelines, all identifiers were removed before statistical analysis. Frequencies and percentages were calculated to provide a demographic profile of the participants and to document their perceptions of the appropriate penalties for the 18 situations involving academic dishonesty. Differences between perceptions of appropriate penalties between class levels were identified by compiling means and standard deviations then running one-way ANOVA's. All tests of significance were determined at the .05 alpha levels. Tukey's HSD was used as a post-hoc test to examine pairwise differences among the three groups (i.e., freshmen, sophomores, and upper classmen). 


\section{FINDINGS}

\section{Participant Demographic Profile}

A total of 266 students enrolled in seven sections of an introductory information systems course participated in this study. Gender was represented by 141 males $(53 \%)$ and 123 females $(47 \%)$. Age ranges included $21(8 \%)$ 18-year-olds, $110(41 \%)$ 19-yearolds, 69 (26\%) 20-year-olds, and $66(25 \%)$ aged 21 and over. There were $132(50 \%)$ freshman, $78(29 \%)$, sophomores and 56 (21\%) upper classmen (juniors and seniors). This profile is presented in Table 1.

\section{Research Question One}

Research question one was asked to document student perceptions of the appropriate penalties for academic dishonesty in an introductory information systems course. Three categories were studied: computer assignments, online testing, and personal responsibility/integrity. (See Table 2.)

Computer Assignments. In four of the six presented situations, over half of the participants reported a grade of " 0 " would be an appropriate penalty. In two of the six situations (copying from a classmates computer screen and completing an individual assignment as a group) approximately forty percent reported the appropriate penalty would be "no penalty", while approximately 40 percent reported a grade of "0" would be appropriate.

Online Testing. In all six of the situations presented, approximately half of the participated reported that the appropriate penalty for cheating during on online test would be to receive a test grade of " 0 ". These situations include: using unauthorized book(s) during testing, copying test answers from a classmate, collaborating with other students during the test, using unauthorized (hidden) notes during the test, getting questions/answers for a test from a student who just completed the test, and text messaging another student for help during the test.

Personal Responsibility and Integrity. In three of the six situations presented (allowing a classmate to copy from their computer screen, leaving completed files on the classroom computer desktop instead of saving on their required flash, and after completing a test, providing questions/answers to a student who will be taking the test later), over half of the participants reported the appropriate penalty would be "no penalty." In two of the situations (allowing a classmate to copy completed files and test messaging answers to a classmate taking the test), over half of the participants reported the appropriate penalty would be a grade of " 0. ." For the situation of completing assignments for a classmate, approximately 40 percent indicated there should be no penalty, while about 40 percent reported the penalty should be a grade of " 0 ." These findings are illustrated in Table 2.

\section{Research Question Two}

Research question two sought to identify significant differences in student perceptions of the appropriate penalties for academic dishonesty based on class level. To test for differences among three groups, a, one-way ANOVA test was run. Within the studied categories that included 18 situations, six areas of significant differences were found. To further identify pairwise differences, Tukey's HSD post hoc tests were run. (See Table 3.)

Computer Assignments. Within the six situations of computer assignments presented, there were four areas of significant differences. Freshman participants reported that copying a classmates completed files and submitting an assignment completed by a classmate/friend warranted significantly lighter penalties as compared with junior/senior participants. Freshman participants reported using completed files found on the classroom computer desktop warranted significantly lighter penalties as compared with sophomore participants. In relation to the significance found between class levels in the situation of using completed files from a flash drive lost by a classmate, no pairwise differences were found. However, a comparison of freshman $M(2.47)$ with sophomore $M(2.79)$ and upper classmen $M(2.8)$ indicates freshman participants perceived using completed files from a flash drive lost by a classmate as warranting lighter penalties than sophomore and junior/senior participants.

Online Testing. Within the six situations of proctored online testing, there was one area of significant difference. Freshman participants reported that collaborating with other students during the test warranted significantly lighter penalties as compared with junior/senior participants.

Personal Integrity and Responsibility. Within the six situations of personal integrity and responsibility, there was one area of significant difference. Freshman participants reported allowing a classmate to copy completed files warranted significantly lighter penalties as compared with sophomore participants. This analysis is displayed in Table 3. 


\section{CONCLUSIONS AND DISCUSSION}

When interpreting the results of the findings of this study it should be noted that following IRB protocol, only students who were willing volunteers participated in the study. The student participants were enrolled in an introductory information systems course. The following conclusions were drawn with these limitations in mind.

Research question one documented student perceptions of the appropriate penalties for academic dishonesty in an introductory information systems course, and research question two analyzed any differences in perceptions between class levels. In the majority of situations involving computer assignments, online testing, and personal responsibility/integrity categories, freshman students perceived the instance of cheating warranted lighter penalties than all other class levels.

The category of computer assignments revealed the most significant differences in perceptions of the appropriate penalties based on class level. The more advanced a student is in their college career, the higher the penalty they perceive is appropriate for cheating on computer assignments. The areas that were not significantly different were copying from a classmate's computer screen and completing an individual assignment as a group. These items were rated as low by all students, as many had indicated this was deserving of "no penalty." Beginning students enter the college environment with beliefs or expectations that might change as they progress. As students mature, they may realize that cheating on assignments, and the possible penalties, are not worth the risk. They also may realize that doing their own work is in their best interest. However, regardless of students' class rank, some incidences that educators perceive as cheating are not perceived as cheating by students. Educators need to reinforce what constitutes cheating and the penalties that will be enforced as a consequence.

In regard to online testing, although freshman means were lower than all other class levels, most students reported that the appropriate penalty for cheating would be to receive a test grade of " 0. " With regard to the situation of collaborating with other students during testing, upperclassmen reported that this penalty should be significantly harsher than freshman. Students rated getting test questions and answers from a student who just completed the test as not deserving as severe a penalty as all other situations. It appears that students consistently agree that penalties for cheating on tests are appropriate, and many accept the penalties as worth the risk. Students need to understand that by giving others test information, they could be hurting their own grade.

Perhaps the most challenging category for educators is in relation to students' perceptions of their personal responsibility and integrity. Overall, the means were lowest in this category for all class levels, and the occurrences of "no penalty" for assisting others to cheat were high. Sophomores did report that allowing a classmate to copy completed files, warranted a significantly harsher penalty when compared with freshman. In the situation of allowing a classmate to copy from their computer screen, junior and senior means were lower than freshman and sophomores.

Educators must find ways to enforce acceptable use policies and acceptable collaborative behaviors. This must include finding ways to assure students do their own work and identifying methods to prevent misuse of technology in the classroom. Software that allows instructors to monitor student use of computers during class may be part of the solution. Instructors and instructional designers may also add features to assignments and examinations that make them unique to an individual student. For example, if each student must process a different set of data in an assigned problem, it might discourage them from copying each other's work.

\section{RECOMMENDATIONS FOR FURTHER RESEARCH}

Based on the findings from this study, the following recommendations for additional research are offered.

1. Since this study found the area of personal responsibility and integrity to be perceived as warranting less of a penalty for academic dishonesty than assignment and testing, further research should focus on this area.

2. As this study focused on students in an introductory information systems course, further research should be conducted in advanced information systems courses and in other subject areas.

3. As this study focused on the demographic variable of class level, other variables based on gender or major should be studied.

4. Since it is important to understand beginning students' beliefs and behaviors, this study should be replicated in three years to identify any 
changes in entering freshman perceptions of the appropriate penalties for academic dishonesty.

5. This study should be replicated in five years to determine any changes in student perceptions of the appropriate penalties for academic dishonesty over time. In response to the unethical/illegal activities in the workplace, the Association to Advance Collegiate Schools of Business (AACSB) has advocated more attention to business ethics. As faculty include a course in ethics to their curriculum, or incorporate ethics into their current courses replicating this study could validate those efforts.

\section{REFERENCES}

1. Burrus, R. T., McGoldrick, K., \& Schuhmann, P. W. (2007). Self-reports of student cheating: Does a definition of cheating matter? Journal of Economics Education, 38(1), 3-16.

2. Broeckelman-Post, M. A. 2008). Faculty and student classroom influences on academic dishonesty. IEEE Transactions on Education, 51(2), 206-211.

3. Campbell, S. (2006). Perceptions of mobile phones in college classrooms: Ringing, cheating, and classroom policies. Communication Education, 55(3), 280-294.

4. Carrel, S. E., Malmstrom, F. V., \& West, J. E. (2008). Peer effects in academic cheating. Journal of Human Resources, 43(1), 173-207.

5. Carter, S. L. \& Punyanunt-Carter, N. M. (2006). Acceptability of treatments for cheating in the college classroom. Journal of Instructional Psychology, 32(3), 212-216.

6. Character Counts! Ethics of American youth 2008 summary. Josephson Institute's 2008 Report Card on the Ethics of American Youth. Available:

www.charactercounts.org/programs/reportcard/ii ndex.html

7. Davy, J. A., Kincaid, J. F., Smith, K. J., \& Trawick, M. A. (2007). An examination of the role of attitudinal characteristics and motivation on the cheating behavior of business students. Ethics \& Behavior, 17(3), 281-302.

8. Kidwell, L., Wozniak, K., \& Laurel, J. (2003). Student reports and faculty perceptions of academic dishonesty. Teaching Business Ethics, 7(3), 205-214.

9. King, C. G., Guyette, R. W., \& Piotrowski, C. (2009). Online exams and cheating: An empirical analysis of business students' views. Journal of Educators Online, 6(1), 1-11.

10. Lavelle, L. (2008). GMAT cheating controversy grows. Business Week Online, 13.

11. Lee, D.E. (2009). Cheating in the classroom: beyond policing. Clearing House, 82(4), 171176.

12. Ma, H. J., Wan, G., \& Lu, E. Y. (2008). Digital cheating and plagiarism in schools. Theory Into Practice, 47(3), 197-203.

13. Megehee, C. M. \& Spake, D. F. (2008). The impact of perceived peer behavior, probable detection and punishment severity on student cheating behavior. Marketing Education Review, 18(2), 5-19.

14. Miller, A., Shoptaugh, C., \& Parkerson, A. (2008). Under reporting of cheating in research using volunteer college students. College Student Journal, 42(2), 326-339.

15. Moran, C. (2008). Cellphones, handy tools for emergency alerts, could be used for cheating during tests. Chronicle of Higher Education, 55(7), A15.

16. Pino, N. W. \& Smith, W. L. (2003). College students and academic dishonesty. College Students Journal, 37(4), 490-500.

17. Rakovski, C. C. \& Levy, E. S. (2007). Academic dishonesty: Perceptions of business students. College Student Journal, 41(2), 466481.

18. Rawwas, M., Swaidan, Z., \& Isakson, H. (2007). A comparative study of the ethical beliefs of master of business administration students in the United States with those in Hong Kong. Journal of Education for Business, 82(3), 146-158.

19. Rettinger, D., \& Kramer, Y. (2009). Situational and personal causes of student cheating. Research in Higher Education, 50(3), 293-313. 
20. Sheard, J., Markham, S., \& Dick, M. (2003). Investigating differences in cheating behaviors of IT undergraduate and graduate students: The maturity and motivation factors. Higher Education Research \& Development, 22(1), 91.

21. Smyth, L. S., Davis, J. R., \& Kroncke, C. O. (2009). Students' perceptions of business ethics: Using cheating as a surrogate for business situations. Journal of Education for Business, 84(4), 229-239.

22. Students cheating found to increase. (2008, December). Education Week, 28(15), 4-4.

23. Volpe, R., Davidson, L., \& Bell, M. C. (2008). Faculty attitudes and behaviors concerning student cheating. College Student Journal, 42(1), 164-175. 
Table 1. Participant Demographic Profile

\begin{tabular}{crr} 
Variable & $\begin{array}{r}\text { Frequency } \\
(\boldsymbol{N = 2 6 6 )}\end{array}$ & $\begin{array}{r}\text { Valid } \\
\text { Percent }\end{array}$ \\
\hline Gender $^{\mathrm{a}}$ & & \\
Male & 141 & 53 \\
Female & 123 & 47
\end{tabular}

Age range

18

$21 \quad 8$

$19 \quad 110 \quad 41$

$20 \quad 69 \quad 26$

$21+\quad 66 \quad 25$

Class Level

Freshman $\quad 132 \quad 50$

$\begin{array}{lll}\text { Sophomore } & 78 & 29\end{array}$

$\begin{array}{lll}\text { Junior/Senior } & 56 & 21\end{array}$

${ }^{a}$ In the variable of Gender, two (2) respondents elected not to respond. 
Table 2. Student Perceptions of Appropriate Penalties for Academic Dishonesty

\begin{tabular}{|c|c|c|c|c|c|}
\hline & 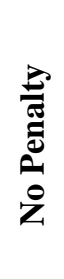 & 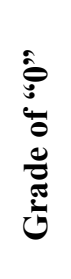 & 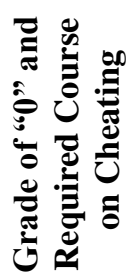 & 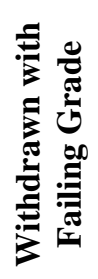 & 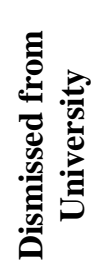 \\
\hline Situation & $\%$ & $\%$ & $\%$ & $\%$ & $\%$ \\
\hline \multicolumn{6}{|l|}{ Computer Assignments } \\
\hline Copies a classmate's completed files & 2 & 73 & 13 & 9 & 3 \\
\hline Copies from a classmate's computer screen & 44 & 44 & 6 & 5 & 1 \\
\hline $\begin{array}{l}\text { Uses completed files from a flash drive lost by a } \\
\text { classmate }\end{array}$ & 2 & 58 & 17 & 21 & 2 \\
\hline Uses completed files found on the desktop & 8 & 66 & 12 & 10 & 3 \\
\hline Submits an assignment completed by a friend/classmate & 1 & 66 & 20 & 12 & 1 \\
\hline Completes an individual assignment with a group & 48 & 41 & 6 & 3 & 2 \\
\hline \multicolumn{6}{|l|}{$\underline{\text { Online Testing }}$} \\
\hline Uses unauthorized book(s) during a test & 10 & 57 & 14 & 16 & 3 \\
\hline Copies test answers from a classmate & 12 & 61 & 16 & 9 & 2 \\
\hline Collaborates with other students during the test & 12 & 59 & 12 & 15 & 2 \\
\hline Uses unauthorized (hidden) notes during a test & 6 & 65 & 13 & 13 & 3 \\
\hline $\begin{array}{l}\text { Gets questions/answers from a student who just } \\
\text { completed the test }\end{array}$ & 36 & 49 & 7 & 6 & 2 \\
\hline Text messages another student for help during the test & 5 & 64 & 12 & 17 & 2 \\
\hline \multicolumn{6}{|l|}{ Personal Responsibility \& Integrity } \\
\hline Allows a classmate to copy completed files & 28 & 59 & 6 & 5 & 2 \\
\hline Allows a classmate to copy from their computer screen & 69 & 24 & 3 & 1 & 3 \\
\hline $\begin{array}{l}\text { Leaves completed files on the desktop instead of saving } \\
\text { on their (required) flash }\end{array}$ & 56 & 34 & 4 & 3 & 3 \\
\hline Completes assignments for a classmate & 42 & 44 & 8 & 4 & 2 \\
\hline $\begin{array}{l}\text { After taking a test, gives questions/answers to a } \\
\text { classmate who will be taking the test later }\end{array}$ & 61 & 23 & 8 & 7 & 1 \\
\hline Text messages answers to a classmate taking a test & 23 & 54 & 9 & 13 & 1 \\
\hline
\end{tabular}


Table 3. Differences In Student Perceptions of the Appropriate Penalties for Academic Dishonesty Based On Class Level

\section{Situation}

\section{Freshman Sophomore Junior/Senior}

$M^{\mathrm{a}}(\mathrm{SD}) \quad M^{\mathrm{a}}(\mathrm{SD}) \quad M^{\mathrm{a}}(\mathrm{SD})$

\section{Computer Assignments}

Copies a classmate's completed files

Copies from a classmate's computer screen

Uses completed files from a flash drive lost by a classmate

Uses completed files found on the desktop

Submits an assignment completed by a friend/classmate

Completes an individual assignment with a group

\section{Online Testing}

Uses unauthorized book(s) during a test

Copies test answers from a classmate

Collaborates with other students during the test

Uses unauthorized (hidden) notes during a test

Gets questions/answers from a student who just completed the test

Text messages another student for help during the test

Personal Responsibility \& Integrity

Allows a classmate to copy completed files Allows a classmate to copy from their computer screen

Leaves completed files on the desktop instead of saving on their (required) flash

Completes assignments for a classmate

After taking a test, gives questions/answers to a classmate who will be taking the test later

Text messages answers to a classmate taking a test

$\begin{array}{llllll}2.27(.71) & 2.35(.77) & 2.61(.93) & 2,263 & 3.6 & .027 * \\ 1.65(.76) & 1.75(.85) & 1.95(1.02) & 2,262 & 2.4 & .093 \\ 2.47(.81) & 2.79(1.02) & 2.80(.88) & 2,263 & 4.5 & .012^{*} \\ 2.17(.77) & 2.58(1.02) & 2.43(.91) & 2,262 & 5.6 & .004 * * \\ 2.30(.67) & 2.54(.78) & 2.69(.86) & 2,262 & 6.0 & .003 * * \\ 1.65(.78) & 1.72(.99) & 1.78(.85) & 2,262 & .47 & .620\end{array}$

$\begin{array}{llllll}2.42(.92) & 2.40(1.01) & 2.64(1.10) & 2,263 & 1.2 & .270 \\ 2.21(.79) & 2.36(.89) & 2.39(1.06) & 2,262 & 1.1 & .330 \\ 2.23(.86) & 2.32(.90) & 2.66(1.08) & 2,262 & 4.3 & .014^{*} \\ 2.39(.86) & 2.40(.94) & 2.46(.91) & 2,261 & .14 & .870 \\ 1.82(.86) & 1.90(.93) & 2.00(.96) & 2,261 & .82 & .440 \\ 2.41(.82) & 2.45(.98) & 2.59(.97) & 2,263 & .79 & .450\end{array}$

$\begin{array}{llllll}1.80(.69) & 2.14(.96) & 2.04(1.03) & 2,262 & 4.2 & .016^{*} \\ 1.38(.67) & 1.59(1.11) & 1.14(.80) & 2,263 & 1.5 & .208 \\ 1.54(.85) & 1.81(1.07) & 1.61(.93) & 2,263 & 2.1 & .129 \\ 1.69(.78) & 1.83(.92) & 2.00(1.03) & 2,262 & 2.4 & .089 \\ 1.55(.93) & 1.69(.98) & 1.75(.99) & 2,263 & 1.0 & .360 \\ 2.10(.91) & 2.25(1.00) & 2.14(1.02) & 2,262 & .58 & .560\end{array}$

a Where 1 = No Penalty, 2 = Grade of " 0 ", 3 = Grade of " 0 " and Required Course on Cheating, $4=$ Withdrawn from Class with Failing Course Grade, 5 = Dismissed from University

$* \mathrm{p}<.05 . * * \mathrm{p}<.01$

Volume X, No. 2, 2009 